\title{
A PERCEPÇÃO AMBIENTAL DE ATORES SOCIAIS DE ESCOLAS PÚBLICAS E PRIVADAS, EM UM BAIRRO DE JOÃO PESSOA (PB)
}

Cynthia Aves Félix de Sousa ${ }^{1}$

Arilde Franco Alves ${ }^{2}$

Tânia Maria de Andrade ${ }^{3}$

Sinara Cybelle Turíbio e Silva Nicodemo ${ }^{4}$

Gustavo Oliveira Vitorino ${ }^{5}$

Resumo: Diante das discussões a respeito dos atuais diagnósticos ambientais, emerge a relevância das instituições de ensino no contexto de degradação ambiental vivenciado atualmente. Desse modo, a presente pesquisa se propôs a analisar comparativamente a percepção do que vem a ser o meio ambiente segundo os estudantes, professores e gestores de escolas públicas e privadas localizadas no bairro Mangabeira, no município de João Pessoa-PB. Os resultados indicaram a presença de diferentes percepções acerca do que vem a ser o meio ambiente, por parte dos atores sociais envolvidos na pesquisa.

Palavras-chave: Atores Institucionais; Educação Ambiental; Meio Ambiente; Percepção Ambiental.

\footnotetext{
1 Universidade Federal da Paraíba. E-mail: cynthiaalvesfs@hotmail.com

2 Instituto Federal da Paraíba. E-mail: francalves11@hotmail.com

3 Instituto Federal da Paraíba. E-mail: Tânia.andrada@ifpb.edu.br

4 Instituto Federal do Rio Grande do Norte. E-mail: sinara.cybelle@gmail.com

${ }^{5}$ Centro Universitário de João Pessoa. E-mail: gustavo_oliveira_vitorino@hotmail.com
} 


\section{Introdução}

O comportamento insustentável da espécie humana, ou mais especificamente do modelo hegemônico de gestão de sociedade tem sido considerado a causa principal dos impactos ambientais diagnosticados, principalmente após a Revolução Industrial. Em escala mundial, os discursos em favor de políticas de proteção do meio ambiente vêm ganhando cada vez mais ressonância, evidenciando a necessidade de se repensar a gestão dos processos que envolvem essa temática.

A educação, seja ela formal ou informal, tem papel importante nesse contexto. Diante do reconhecimento das causas dos desequilíbrios ambientais decorrentes das atividades humanas, cada vez mais se faz necessário que as discussões sobre Educação Ambiental evoluam de modo a contribuir para uma construção de uma educação baseada em princípios de sustentabilidade.

No artigo 225 da Constituição Federal de 1988 é aludido o direito e a responsabilidade de cada cidadão e do poder público para com o Meio Ambiente, onde afirma que é direito de todos viverem em um meio ambiente ecologicamente equilibrado. Mas para isto é necessário garantir a sua preservação para as gerações presentes e futuras (BRASIL, 2015).

Ainda no mesmo artigo, em referência ao alcance de um meio ambiente ecologicamente equilibrado, no parágrafo $1^{\circ}$, inciso $\mathrm{VI}$ é esclarecido que o poder público é incumbido de promover a Educação Ambiental em todos os níveis de ensino. Este mesmo inciso por sua vez regulamenta a Política Nacional de Educação Ambiental (Lei n. 9.795, de 27 de abril de 1999), que em seu Art. 3o, inciso II determina a responsabilidade das instituições educativas na promoção da Educação Ambiental de maneira integrada aos programas educacionais desenvolvidos (BRASIL, 2015).

Nessa perspectiva, Carvalho (2006) aborda a Educação Ambiental como ação educativa, principalmente responsável pela formação de atitudes e sensibilidades, sobretudo relacionadas ao meio ambiente. De acordo com a autora, na legislação, a Educação Ambiental prima pelos aspectos da transversalidade, da continuidade, da permanência e da interdisciplinaridade, formalizando a obrigatoriedade em todos os níveis de ensino sendo considerada essencial a sua presença nas matrizes curriculares do Ensino Fundamental.

Diante disto, a Educação Ambiental no campo escolar, deve ser aplicada de maneira ampla, envolver toda a prática educacional, buscando uma percepção e ação reflexiva e crítica da realidade, proporcionando noções de responsabilidade, cooperação e solidariedade.

"O termo percepção deriva do latim perceptio, correspondente à compreensão/percepção ou percipere: apreender através dos sentidos" (FIGUEIREDO, 2011 p. 39). Ela pode ser entendida como processo cognitivo de apreensão das informações ou estímulos presentes no ambiente. Ocorre através dos processos perceptivos, a partir dos interesses e necessidades, que se estruturam e organizam a interface entre realidade e mundo, selecionando-as, armazenando-as, e conferindo-lhes significados (HAMMES, 2004; OLIVEIRA, 2006).

A percepção ambiental pode ser definida como sendo a tomada de consciência do ambiente pelo homem, ou seja, é o ato de cada indivíduo, inserido no ambiente, de perceber, reagir, agir e responder a diferentes ações no e sobre o meio (XAVIER; NISHIJIMA, 2010). A percepção do indivíduo e a Educação Ambiental estão intimamente relacionadas de modo que a Educação Ambiental proporcionada a ele,

revista brasileira educação ambiental 
tanto formal como a informal, participa significativamente do modelamento de sua percepção do ambiente, e esta, por sua vez, atuará na forma que ele age no meio em que está.

O ambiente escolar, independente da realidade socioeconômica, deve ser capaz de exercer influência positiva no processo de formação educacional do indivíduo. Assim, a implementação de projetos e ações relacionadas à conscientização ambiental destas instituições é capaz de mudar a realidade da percepção ambiental dos atores sociais inseridos neste contexto e de certa forma contribuir para o desenvolvimento sustentável global a partir da escala local.

No entanto, para que tais ações sejam realizadas com eficácia e eficiência, ferramentas como o diagnóstico da percepção ambiental dos atores sociais envolvidos se faz imprescindível no desenvolvimento e concretização de propostas de conscientização ambiental para estudantes, docentes e gestores. Assim, a gestão ambiental, enquanto indutora da transformação social, não deve ser colocada à margem da função social da escola de formar indivíduos conscientes de sua realidade (ARAGÃO et al., 2011).

Diante do exposto, esta pesquisa objetivou analisar comparativamente a percepção do que vem a ser o meio ambiente, segundo os estudantes, docentes e gestores de escolas públicas e privadas do bairro de Mangabeira, no município de João Pessoa-PB. A importância desta investigação se justifica pela necessidade de mudança no contexto ambiental da atualidade, tendo como ênfase a educação formal como uma ferramenta transformadora das práticas que levam a degradação do meio ambiente.

\section{Metodologia}

A pesquisa tratou-se de um estudo de caso, caracterizada pelo seu cunho exploratório com abordagens quantitativas e qualitativas. A mesma se deu através da observação extensiva, seguida de aplicação de questionário - o instrumento de coleta dos dados primários. Para a análise das respostas foi utilizado o Estudo de Percepção Ambiental.

Como instrumentos principais de coleta de dados, foram elaborados questionários que foram previamente submetidos ao CEP- Comitê de Ética em Pesquisa, onde foi avaliado e aprovado (número do parecer consubstancial: 191.260). Assim como os questionários, os Termos de Assentimento e de Consentimento Livre e Esclarecido TCLE foram submetidos para a mesma avaliação.

\section{Área de estudo}

João Pessoa, uma cidade brasileira de médio porte, segundo o IBGE (2010), localiza-se no extremo oriental do estado da Paraíba e ocupa uma área de $210,45 \mathrm{Km}^{2}$. Localiza-se entre as Latitudes $7^{\circ} 15^{\prime} 0^{\prime \prime} \mathrm{S}$ e $7^{\circ} 3^{\prime} 0^{\prime \prime} \mathrm{S}$ e longitudes $34^{\circ} 52^{\prime} \mathrm{W}$ e $34^{\circ} 48^{\prime} 0^{\prime \prime} \mathrm{W}$ (Figura 1). 


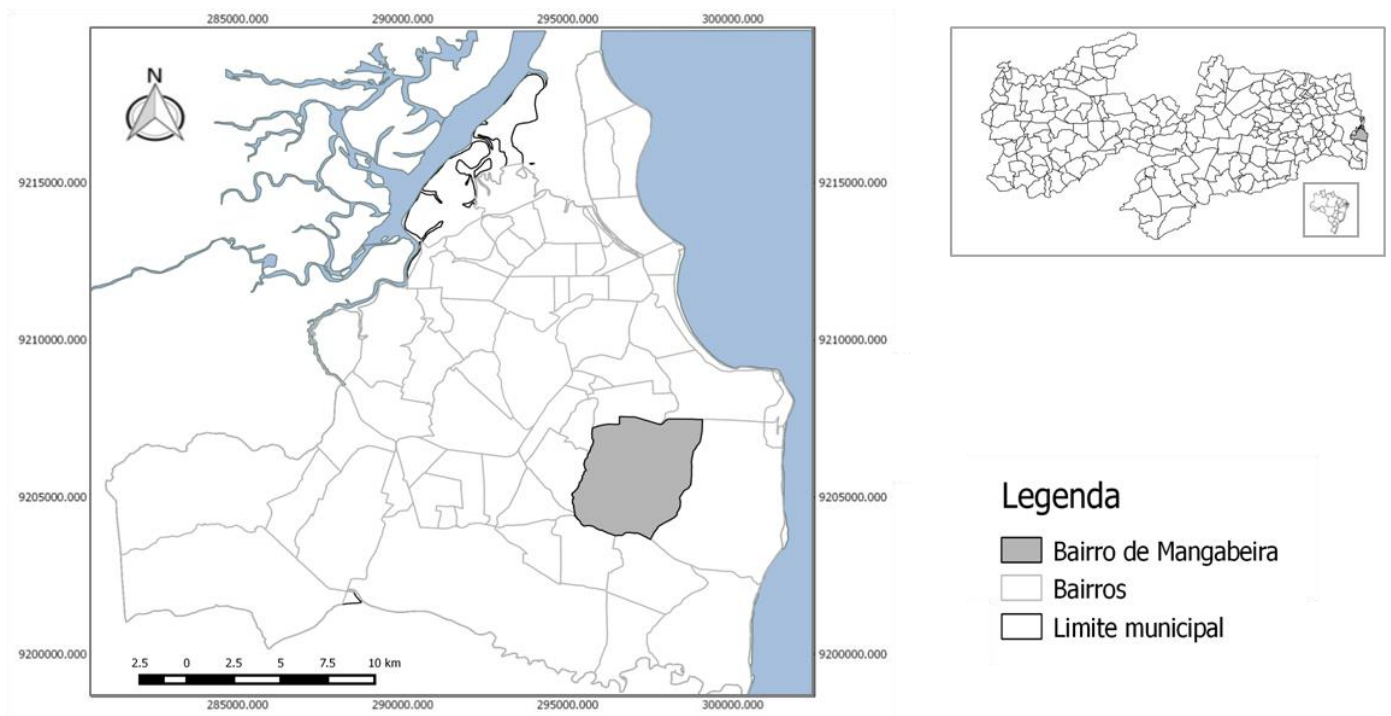

Figura 1: Localização do município de João Pessoa, no mapa da Paraíba

Fonte: Elaboração própria (2017)

A cidade atualmente abriga 723.515 habitantes (IBGE, 2010) e junto com o seu crescimento e desenvolvimento urbano, tem apresentado diversos problemas de ordem ambiental, devido, em parte, ao fato de as pessoas não serem sensibilizadas a cuidar do seu meio ambiente. Dentre os infortúnios destacam-se a depredação do patrimônio público, desperdício de recursos como a água, formações de lixões em rios e terrenos baldios, além da queima de resíduos a céu aberto (SOUSA et al., 2016).

\section{Dos dados da pesquisa}

Os elementos institucionais considerados neste estudo foram às escolas de ensino fundamental, categorizadas como Públicas e Particulares; a dimensão amostral, por sua vez foi definida como Discentes e Docentes.

A amostra de discentes contou com 450 estudantes, sendo 187 estudantes das escolas particulares (representando $93,4 \%$ do valor total) e 263 estudantes da rede pública municipal de ensino (representando 90,9\% do valor total).

Para saber a amostra ideal desta dimensão utilizou-se uma calculadora online para cálculos amostrais para amostragem aleatória simples sobre variáveis categóricas. Com erro amostral de $2 \%$ e nível de confiança de $95 \%$ alcançamos o número ideal de nossas amostras.

Segundo Santos (2016), para saber de quanto seria este valor, utiliza-se a seguinte fórmula:

$$
n=\frac{N \cdot Z^{2} \cdot P \cdot(1-P)}{Z^{2} \cdot P \cdot(1-P)=e^{2} \cdot(N-1)}
$$

Onde:

$\mathrm{n}$ - amostra calculada

$\mathrm{N}$ - população

Z - variável normal padronizada associada ao nível de confiança

$\mathrm{p}$ - verdadeira probabilidade do evento

e - erro amostral. 
Para a amostra de docentes, foram considerados como participantes os professores presentes nas salas de aula no momento da aplicação dos questionários com os estudantes, totalizando-se 23 professores, sendo 13 das escolas públicas e 10 das particulares.

A amostra de gestores participantes da pesquisa foi composta pelos diretores das instituições de ensino de acordo com o acesso a eles, ou seja, os diretores que estavam presentes nas escolas, durante a aplicação dos questionários com os demais participantes.

\section{Resultados e discussões}

Diante dos diagnósticos de degradação ambiental, muitas vezes irreversíveis, sejam eles em escala local e até mesmo global, as discussões acerca de medidas de prevenção tomam cada vem mais ressonância evidenciando a necessidade da presença de uma Educação Ambiental cada vez mais eficiente e integradora. Nesse sentido, Nogueira et al. (2015) assevera que a educação exerce papel fundamental no processo de mudança de hábitos e atitudes culturais impróprias para a atual situação da sociedade diante das questões ambientais.

No que tange a essas mudanças de hábitos, acredita-se que a Educação Ambiental pode oferecer subsídios para a prevenção de processos de degradações ambientais. Assim, no sentido de identificar qual a definição mais próxima da que os estudantes consideram expressar o significado do que vem a ser meio ambiente, foi solicitado que respondessem a uma questão (Figura 2, próxima página).

Conforme foi apresentado, a variável que recebeu maior importância foi o referente à alternativa $\mathrm{B}$, apresentando maioria tanto entre os estudantes de escolas particulares, quanto entre os estudantes das escolas públicas. Acredita-se que esse entendimento expressa a compreensão do meio ambiente enquanto fonte de recursos, necessários a existência da vida humana.

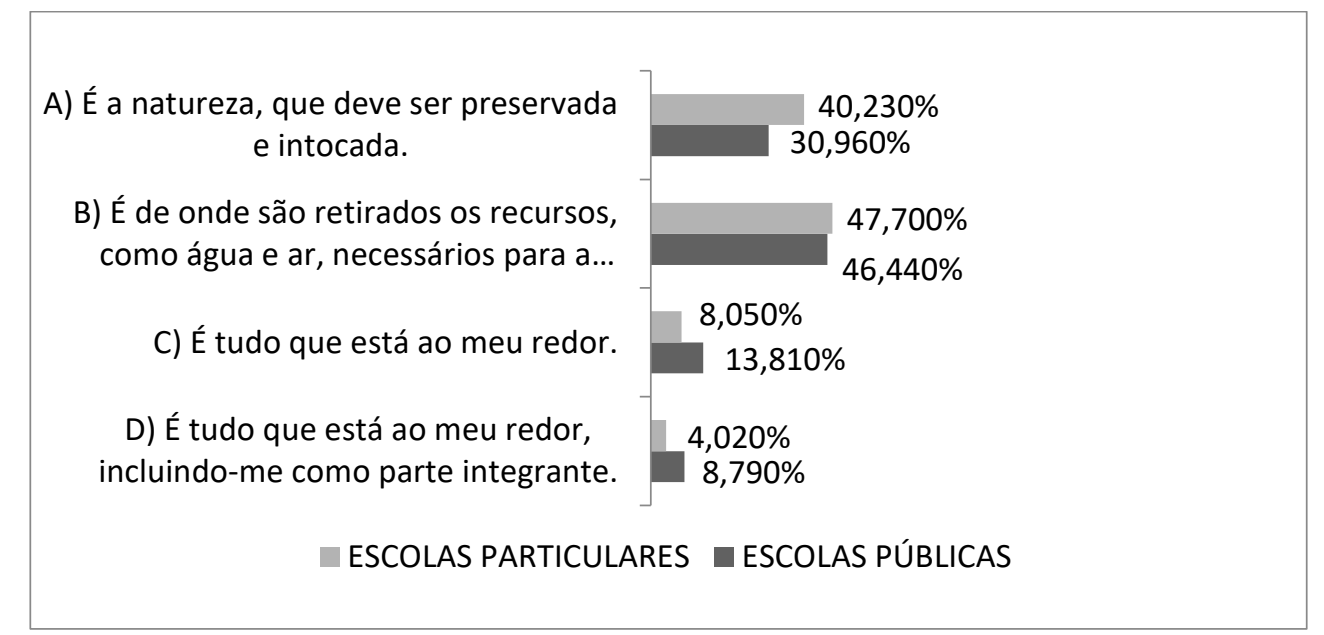

Figura 2: Para você, o meio ambiente é... (estudantes)

Fonte: Dados da pesquisa (2017)

\section{Fonte: Dados da pesquisa (2017)}

Em contraponto a compreensão supracitada, a segunda alternativa mais escolhida foi a A ( $40 \%$ para escolas particulares e $31 \%$ para as públicas), que apresenta o meio ambiente como um espaço natural e que deve ser intocado. Enquanto espaço intocável, o ambiente, nesse caso, teria menor influência direta no dia-dia das pessoas, Revbea, São Paulo, V. 12, № 4: 180-191, 2017. 
não havendo uma integração evidente entre as relações homem-meio ambiente, sejam elas positivas ou negativas.

Quanto à alternativa $\mathrm{C}$, que se referia ao meio ambiente como tudo ao redor do indivíduo, é posta a reflexão de que para esses atores sociais, pode não haver ou não ser expressa a legitimação do ambiente enquanto parte daquilo que o torna indivíduo e, enquanto resultado das interações entre os indivíduos sobre o lugar no qual interage. De acordo com Nogueira et al. (2015) apesar de a compreensão do que vem a ser o meio ambiente deva estar voltada para definições mais integradas, envolvendo tanto o ambiente social, como político, e escolar, por exemplo, a realidade nos mostra que em majoritariamente esta visão está associada fortemente apenas para o meio natural.

A alternativa $D$ admite o meio ambiente como tudo ao redor do indivíduo, inclusive ele próprio, como parte necessária para a sua composição. Trata-se de uma visão considerada integradora, possibilitando o reconhecimento da necessidade da proteção do ambiente enquanto espaço de vivência, enquanto fonte de recursos, enquanto espaço de lazer e contemplação e principalmente enquanto parte do próprio indivíduo.

Nessa perspectiva, a escolha desta opção pela minoria dos estudantes denota um ponto a ser profundamente estudado e considerado nos processos de planejamento e efetivação das intervenções por meio da Educação Ambiental. Assim, para Nogueira et al. (2015), a Educação Ambiental é um instrumento educacional extremamente necessário, de modo a contribuir satisfatoriamente na construção de diferenciações e especificações para tal conceito.

$\mathrm{Na}$ atual crise ambiental, a necessidade de trabalhar junto aos jovens, temáticas ambientais, é fundamental para que haja uma mudança de atitudes em relação às questões ambientais (CASTOLDI, BERNARDI e POLINRSKI, 2009). Essas atitudes referem-se primordialmente aos impactos ambientais negativos, considerados como problemas, por afetarem a qualidade dos ambientes e da vida humana e dos animais. A escola, por tanto, demonstra possuir um papel relevante para 0 desenvolvimento destas capacidades.

A partir da reflexão acima, foi solicitado que os estudantes marcassem quais das alternativas disponibilizadas eram, de acordo com eles, problemas ambientais (Figura 3).

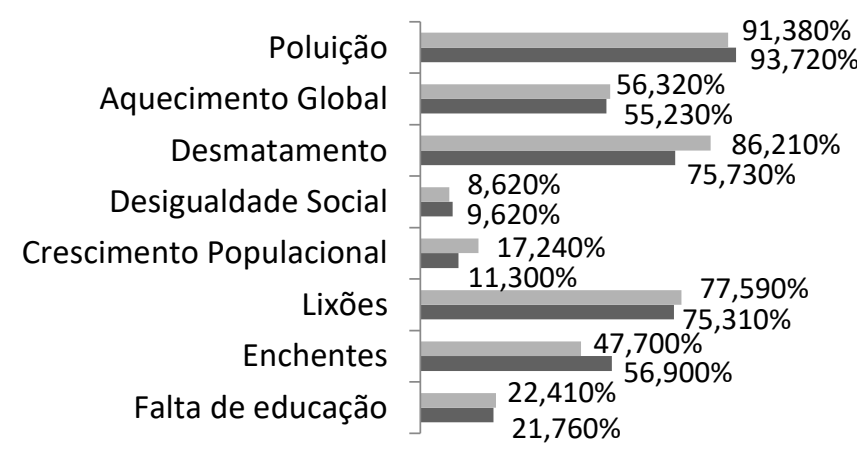

ESCOLAS PARTICULARES $\quad$ ESCOLAS PÚBLICAS

Figura 3: Alternativas das quais você considera serem problemas ambientais (estudantes). Fonte: Dados da pesquisa (2017) 
As alternativas que receberam as maiores marcações foram poluição, desmatamento e lixões, representando, segundo os entrevistados, a ligação mais evidente com o ambiente. Em sua pesquisa, Prochnow e Farias (2015), mostraram que nas poucas representações de impacto ambiental, expressas por meio de desenhos feitos por estudantes do ensino fundamental, o despejo de lixo apresentou o maior destaque, seguido do esgoto a céu aberto da fumaça veicular.

O aquecimento global, embora tão citado nas mídias, é considerado um problema ambiental para menos de $60 \%$ dos estudantes de ambas as redes de ensino. A questão das enchentes nas cidades (com menos de $60 \%$ de marcações) também evidenciou uma necessidade de tratar melhor destas questões relacionadas à problemática ambiental.

As variáveis menos abordadas foram as de cunho predominantemente social, ou seja, desigualdade social, crescimento populacional e falta de educação. Isso mostra que os estudantes possuem uma visão da problemática ambiental ainda restrita, pois o fator social, para eles, não está associado ao ambiental.

Os educadores responderam aos mesmos questionamentos, objetivando identificar a percepção deles e suas principais semelhanças com as de seus estudantes, de modo a identificar até que ponto ocorre ou não uma consciência ou influência dos docentes na construção da percepção ambiental dos estudantes, além de identificar as carências a serem sanadas. Os resultados da pesquisa de Costa et al. (2012), mostraram que para os professores entrevistados, no que concerne a definição de meio ambiente, esta foi categorizada em duas vertentes, a naturalista e a antropocêntrica, havendo uma maior predominância da visão naturalista em relação ao meio ambiente.

Desse modo, o primeiro questionamento para os professores se referiu à concepção de meio ambiente segundo eles (Figura 4).

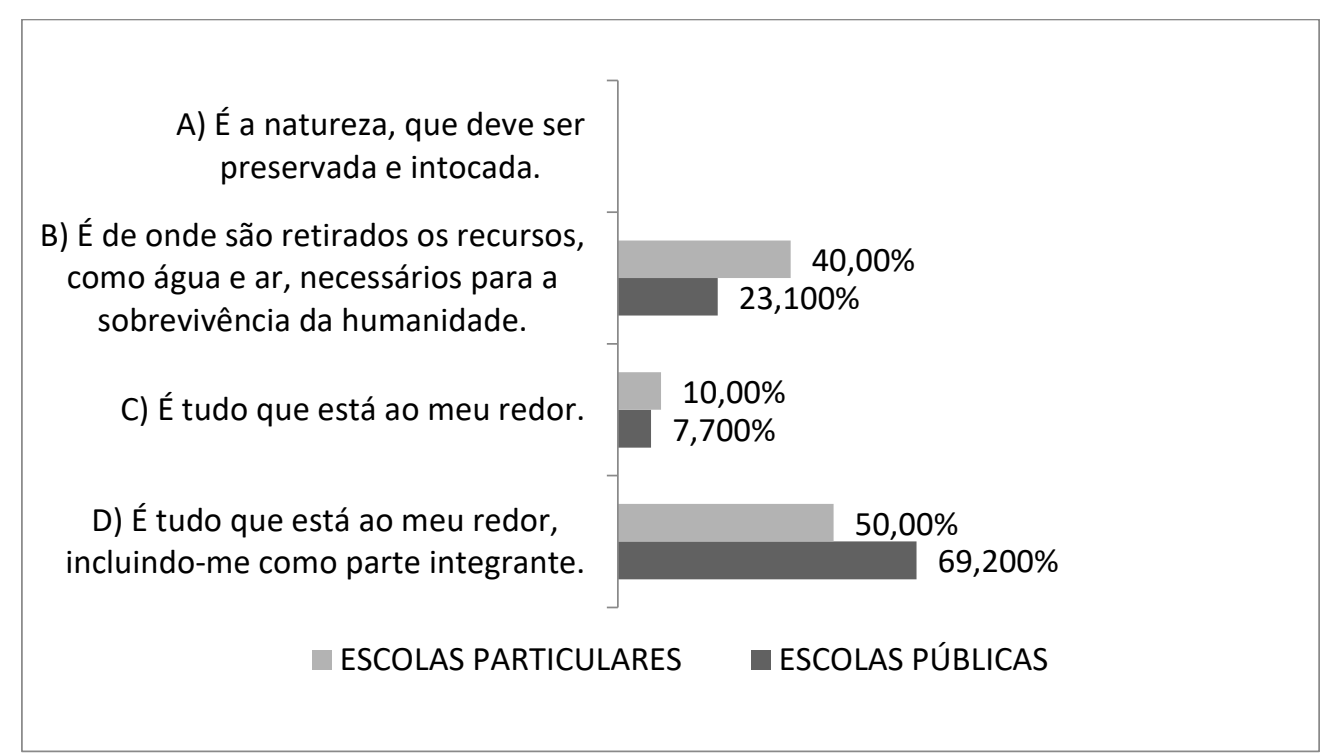

Figura 4: Para você, meio ambiente é... (docentes).

Fonte: Dados da pesquisa (2017) marcações por parte dos docentes para a alternativa A. De um modo geral, os professores de ambas as classificações de instituições de ensino acreditam que o meio ambiente é tudo que está ao redor, incluindo eles próprios como parte integrante. Os Revbea, São Paulo, V. 12, № 4: 180-191, 2017. 
docentes das instituições públicas, especificamente, obtiveram uma porcentagem maior na escolha, com $69,2 \%$, o que mostra que eles possuem uma visão mais integrada do que representa 0 ambiente.

De maneira curiosa, foi possível observar que na alternativa $B$, a maior expressão de resposta esteve com os professores das escolas particulares, com $40 \%$ de representação. Esta alternativa caracteriza-se por uma visão considerada que enxerga o meio ambiente como uma fonte de recursos.

A questão que segue, buscou identificar os problemas de ordem ambiental, segundo os docentes, conforme revela a Figura 5.

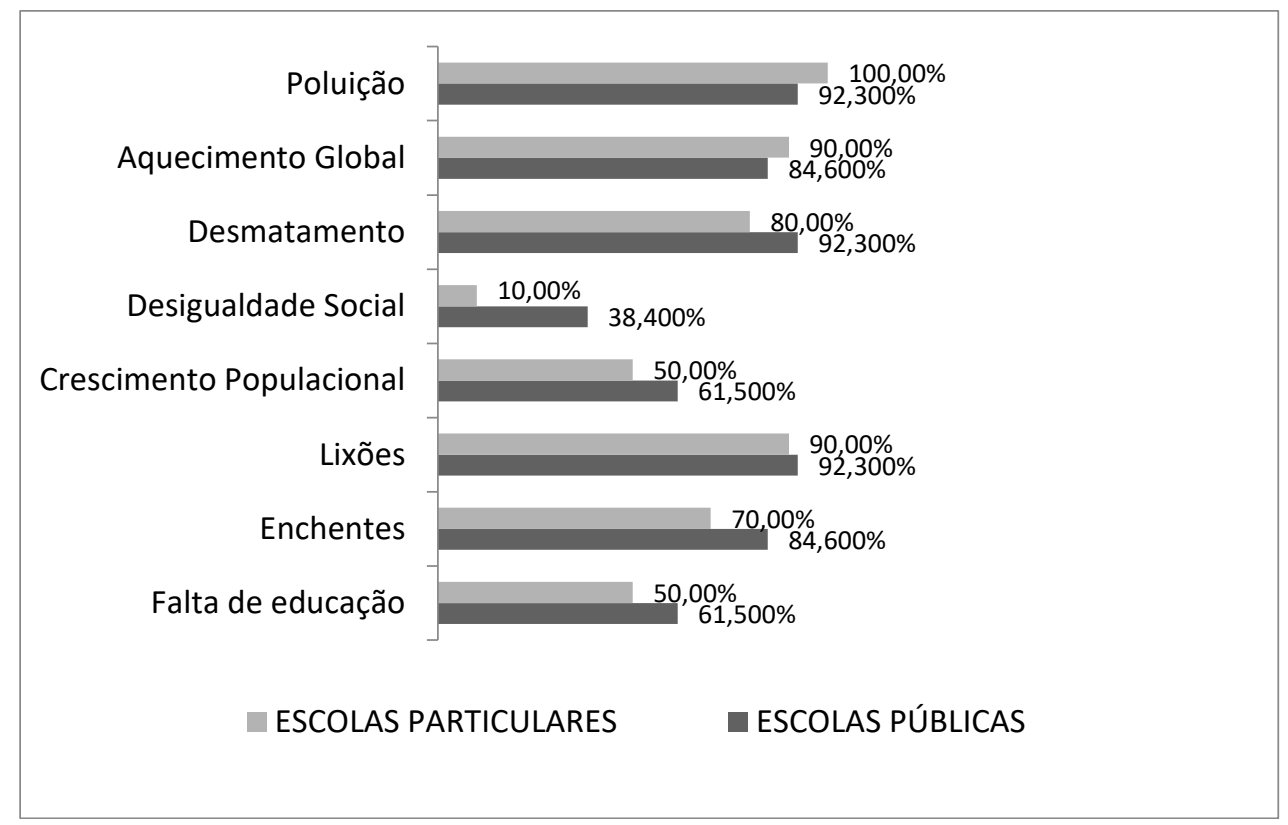

Figura 5: Marque as alternativas abaixo, das quais você considera serem problemas ambientais. (docentes). Fonte: Dados da Pesquisa (2017)

Nesse questionamento, os entrevistados puderam optar por quantas alternativas julgasse necessário. As mais citadas pelos professores das escolas particulares e públicas foram poluição, aquecimento global, desmatamento, lixões e enchentes, com mais de $70 \%$ de representação.

Quanto às alternativas de cunho mais social, foi observado que a desigualdade social, o crescimento populacional e o crescimento populacional foram as que apresentaram menores percentuais de escolha. Isto se deve ao fato de eles, provavelmente, não observarem uma correlação entre os diversos aspectos das problemáticas sociais com os problemas ambientais, pois alguns docentes não percebem o ser humano como elemento integrado ao meio ambiente.

No entanto, ressalta-se que quando comparadas as marcações, é verificado que $38 \%$ dos professores das escolas públicas consideram a desigualdade social como um problema de cunho ambiental, enquanto $10 \%$ dos docentes das escolas particulares partilham dessa certeza. Esse resultado pode indicar uma melhor capacidade de visão integradora devido à vivência mais recorrente com a realidade social menos abastada.

No meio urbano, as populações que mais vivenciam problemas oriundos da falta de saneamento ambiental, como por exemplo, poluição dos rios por efluentes, 
formação de pontos de lixo e disseminação de doenças, majoritariamente são de baixa renda (CUNHA et al., 2017; OLIVEIRA et al., 2017).

Os gestores das intuições que estavam presentes nos momentos de aplicação de questionário também responderam a um questionário. Os questionamentos foram os mesmos direcionados para os estudantes e para os docentes (Figura 7).

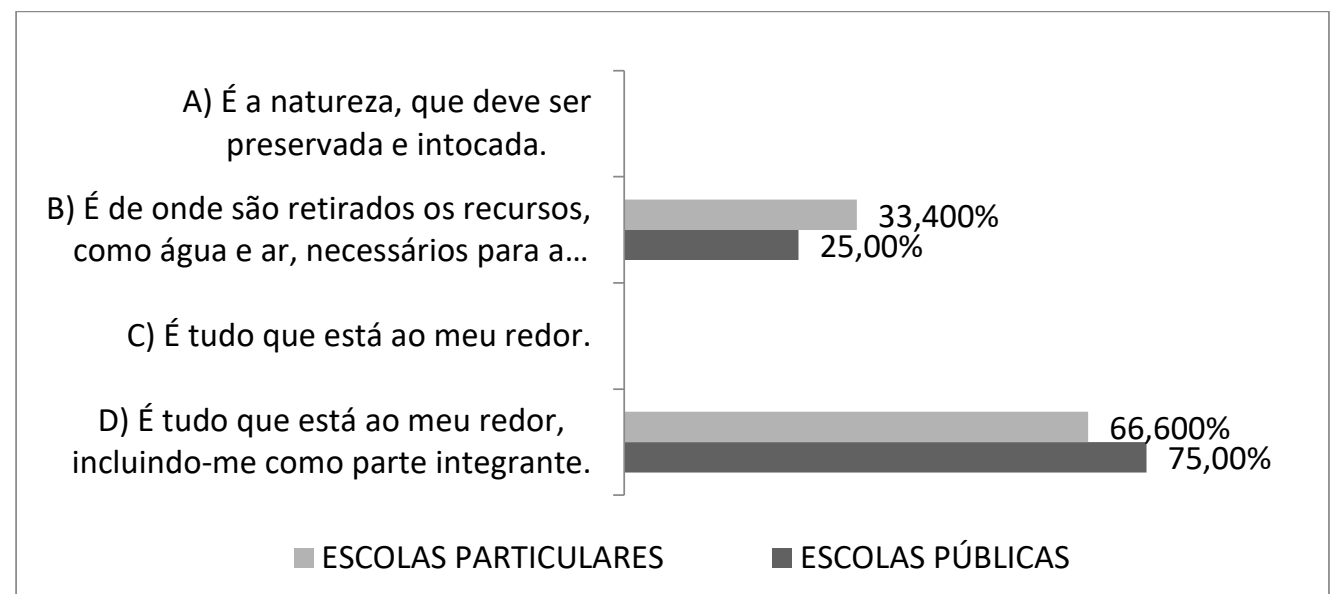

Figura 7: Para você, meio ambiente é... (gestores). Fonte: Dados da pesquisa (2017)

A marcação da letra B merece um olhar mais crítico, tendo em vista a necessidade atual de se enxergar o meio ambiente de uma maneira mais holística. Nesse entendimento, a visão antropocêntrica do meio ambiente, ou seja, aquela cuja concepção de meio ambiente se aproxima da compreensão do mesmo como uma fonte de recursos existentes para satisfazer o ser humano, ainda é bastante fragmentada, e precisa ser substituída por uma visão holística, sistêmica e interdisciplinar (MARTINS, 2003; COSTA et al., 2012).

A maioria dos entrevistados, no entanto, concebe o ambiente de uma maneira mais holística, ocorrendo uma diferença de cerca de $10 \%$ entre os quantitativos (75\% referente às escolas particulares e $66,6 \%$ referente às escolas públicas). O quantitativo das respostas se assemelha bastante a dos professores, trazendo um ponto positivo no que se refere aos planejamentos de ações de Educação Ambiental nas escolas.

Apesar da definição de meio ambiente ter se apresentado holística na maioria das marcações, o fator social na problemática ambiental ainda foi pouco citado, o que nos mostra que o conceito é conhecido, mas pode não estar internalizado ainda (Figura 8, próxima página).

Em parte, isso pôde ser observado ao passo que os entrevistados consideraram como problemas ambientais alguns fatores sociais, exceto o crescimento populacional, que não foi citado pelos gestores das escolas públicas. Cabe lembrar que esta variável é uma das peças chaves para o controle no uso e manejo dos recursos naturais e da poluição ambiental tanto na escala local quanto na escala global. 


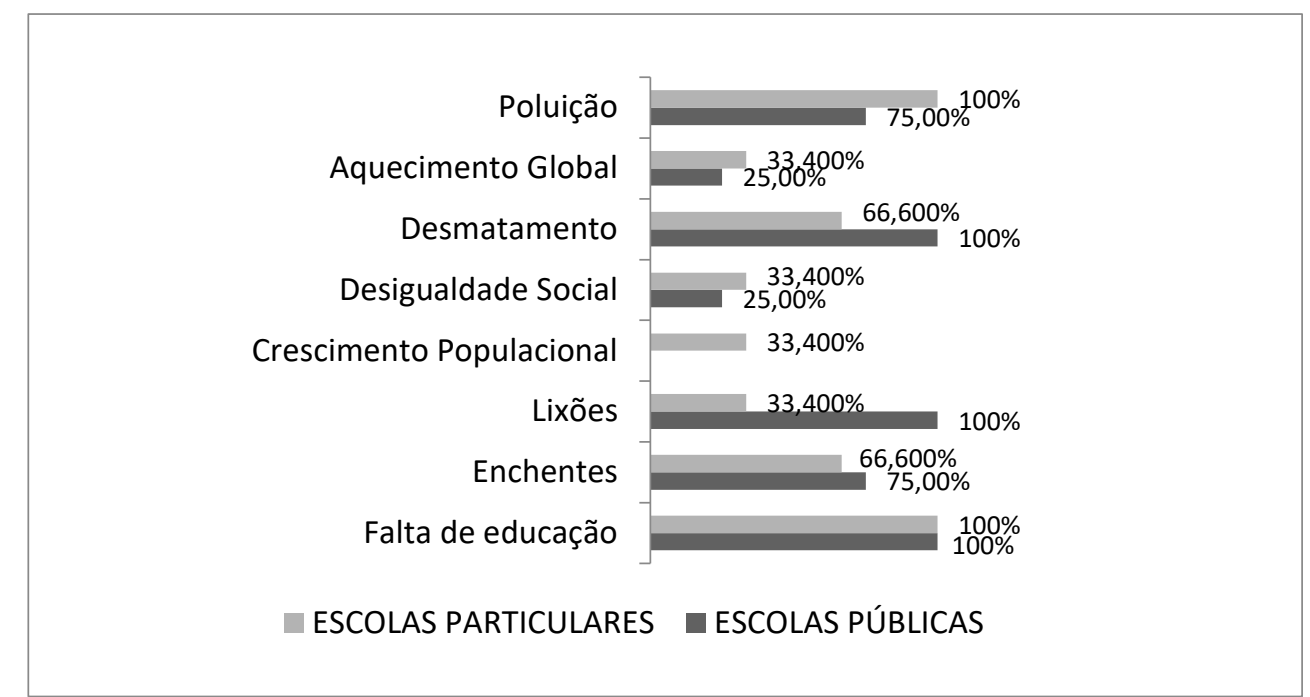

Figura 8: Marque as alternativas abaixo, das quais você considera serem problemas ambientais. (gestores). Fonte: Dados da Pesquisa (2017)

O aquecimento global recebeu poucas marcações por parte dos gestores das instituições particulares e públicas (33,4\% e $25 \%$ ), diferentemente dos resultados referentes aos docentes $A$ questão do crescimento populacional foi considerada por poucos destes atores sociais (33\% das particulares e nenhuma das públicas).

Foi verificado que todos os gestores citaram a falta de educação como um problema ambiental, enquanto que cerca da metade dos docentes escolheram a mesma alternativa. Este resultado indica a capacidade dos gestores em relacionar a problemática ambiental com as ações humanas determinadas pela sua consciência ambiental construída pela educação.

A identificação das concepções acerca do que vem a ser o meio ambiente, segundo diferentes atores sociais que compõem o contexto escolar, permite uma visualização ampla da percepção ambiental deles, possibilitando o desenvolvimento de estratégias mais eficientes de Educação Ambiental.

A partir de atividades de Educação Ambiental com estudantes do ensino fundamental Archanjo e Haga, (2014) concluíram que os alunos mostraram-se interessados e preocupados com a questão ambiental, sendo possível perceber que a maioria se sensibilizou e se motivou a realizar ações como plantar árvores, por exemplo. De acordo com autores, foi observada uma mudança significativa inclusive de comportamento, em relação à disciplina em sala de aula.

Desse modo, a Educação Ambiental integraliza conhecimentos, valores e atitudes que quando contextualizados, promovem grandes avanços em cada momento da aprendizagem. Todavia, para alcançar resultados significativos, essas estratégias não devem ser ações esporádicas. (PROCHNOW; FARIAS 2015).

\section{Conclusões}

Nesta pesquisa, foi realizado um estudo comparativo entre as percepções ambientais de atores sociais de escolas públicas e privadas. Desse modo, conclui-se que nas instituições participantes, a maioria dos estudantes das escolas públicas, em comparação com os estudantes das escolas particulares, apresenta uma visão mais 
integrada do que vem a ser o meio ambiente. No entanto, essa discrepância deve ser mais investigada no sentido de se observar até que ponto a realidade socioeconômica e educacional de cada ator interfere neste aspecto.

Quanto aos docentes, conclui-se que em ambas as redes de ensino, estes possuem percepções semelhantes. No que tange aos gestores, estes apresentaram maiores divergências quando comparadas entre as duas redes de ensino, especialmente no que tange ao tema problemas ambientais, visto que os gestores das instituições públicas apresentaram uma concepção mais holística.

Entre a percepção ambiental de docentes e gestores, ocorreu um baixo desacordo, havendo certa polarização entre uma visão mais integrada do meio ambiente e uma visão que não considera o ator social como parte integrante do mesmo. Concluise que entre o grupo de estudantes, de docentes e de gestores entrevistados, os das escolas públicas em geral, possuem uma percepção mais integrada sobre o meio ambiente. No entanto, foi verificada diferença entre a percepção dos estudantes e os demais atores institucionais. Assim, recomenda-se o aprofundamento para que seja observado se a discrepância tem relação com a idade, com o nível de escolaridade e/ou com o acúmulo de conhecimentos acerca da temática.

Assim, visto que não há uma aparente homogeneidade quanto à percepção do que vem a ser meio ambiente, no que tange aos atores sociais e inclusive às redes de ensino, é indispensável uma caracterização prévia. Desse modo, provavelmente a concretização de propostas de estratégias de Educação Ambiental será mais eficiente.

Agradecimentos: Ao Instituto Federal de educação, ciência e tecnologia da Paraíba (IFPB) pelo apoio no desenvolvimento da pesquisa e, as escolas públicas e privadas que contribuíram com a sua participação.

\section{Referências}

ARAGÃO, J. P. G. V; SANTOS, K. M. B.; SILVA, M. M.; Gestão Ambiental e Escola: a construção de uma atitude ambiental. Ambiente \& Educação, Rio Grande, v.16, n.2, p. 27-40. 2011.

ARCHANJO, N.P.; HAGA, K.I. Ensino de Educação Ambiental: uma experiência com alunos do primeiro ciclo do ensino fundamental). Revista Brasileira de Educação Ambiental. São Paulo, n. 9, n. 1, p.169-183. 2014.

BRASIL. Lei № 6.938. Dispõe sobre a Política Nacional do Meio Ambiente, seus fins e mecanismos de formulação e aplicação, e dá outras providências. Brasília, DF, 31 de Agosto de 1981. Disponível em: http://www.planalto.gov.br/ccivil 03/leis/l6938.htm. Acesso em: 25 /Jul. 2015.

BRASIL. Constituição (1988). Constituição da República Federativa do Brasil de 1988. Art. $225 . \quad$ Disponível em: http://www.planalto.gov.br/ccivil 03/constituicao/constituicaocompilado.htm. Acesso em: 09 de ago. de 2015.

BRASIL. Lei № 9. 795. Dispõe sobre a Educação Ambiental, institui a Política Nacional de Educação Ambiental e dá outras providências. Brasília, DF, 27 de Abril de 1999. Disponível em: http://www.planalto.gov.br/ccivil 03/leis/l9795.htm. Acesso em: 05 de Ago. de 2015. 
CASTOLDI, R., BERNARDI, R., POLINARSKI, Celso Aparecido. Percepção dos problemas ambientais por alunos de ensino médio. Revista Brasileira de Ciência, Tecnologia e Sociedade. v.1, n.1, p.56-80, 2009.

CARVALHO, I.C.M. Educação Ambiental: a formação do sujeito ecológico. São Paulo: Cortez, 2006.

COSTA J.R.; SOARES, J E.C.; TÁPIA-CORAL, S.; MOTA, A.M. A percepção ambiental do corpo docente de uma escola pública rural em Manaus (Amazonas). Revista Brasileira de Educação Ambiental, Rio Grande, v.7 p. 63-67, 2012.

CUNHA, J.P.S.; LUCENA, R.C.F., SOUSA, C.A.F.S. Monitoramento do uso e ocupação de Áreas de Preservação Permanentes urbanas com o apoio de geotecnologias: O caso do rio Jaguaribe em João Pessoa-PB. Revista Nacional de Gerenciamento de Cidades. v. 5, n. 30, 2017.

FIGUEIREDO, L.V.R. Percepção ambiental em uma unidade de conservação de proteção integral. 2011. 475p Dissertação (Mestrado em Desenvolvimento Social) Universidade Estadual de Montes Claros - Unimontes. 2011.

HAMMES, V.S. Proposta metodológica de macroeducação. v.2. São Paulo: Globo, 2004.

IBGE. Censo Demográfico 2010. 2010.

MARTINS, M.T.J. Escola, meio ambiente e relações: reprodução ou mudança? 2003. 59 f. Trabalho de Conclusão de Curso (Monografia) - Faculdade de Educação, Universidade do Estado do Rio de Janeiro, Rio de Janeiro, 2003.

NOGUEIRA, J.V.D.; NOGUEIRA, N.D.; NOGUEIRA, C.F.C. Percepção de educadores do município de Manaíra (PB) sobre a importância do debate da problemática dos resíduos sólidos e o uso da prática de encenação teatral como instrumento didático para a Educação Ambiental no ensino básico). Revista Brasileira de Educação Ambiental. São Paulo, v. 10, n. 1, p. 291-300. 2015.

OLIVEIRA, N.A.S. A Educação Ambiental e a Percepção Fenomenológica, através de Mapas Mentais. Revista Eletrônica do Mestrado em Educação Ambiental, v. 16, Jan./jun. p. 32-46, 2006.

OLIVEIRA, B.M.; SOUSA, C.A.F.; CAMPOS, J.C.B.; BRITO, H.C. Espraiamento urbano e suas consequências: Um estudo de caso em Barra de Gramame, na cidade de João Pessoa - PB. In: SEABRA, G. (Org.). Tierra: Naturaleza, Biodiversidad y Sustentabilidad. 1ed. San José, C.R. : Jade, 2017. v.1, p. 889-897.

PROCHNOW, T.R.; FARIAS, M.E. Percepção dos impactos ambientais locais: pesquisando ações de educação para o desenvolvimento sustentável na periferia de Canoas/RS Instrumento: Revista Instrumento., Juiz de Fora, v. 17, n. 1, jan./jun. 2015. SANTOS, G.E.O. Cálculo amostral: calculadora on-line. Disponível em: $<$ http://www.calculoamostral.vai.la $>$. Acesso em: 24 de fevereiro de 2016.

SOUSA, C.A.F.; ALMEIDA, S.V. N. C.; SILVEIRA, J. A. R. Espaços livres públicos e proteção ambiental: um estudo de caso sobre as praças públicas da zona sul da cidade de João Pessoa, PB. Cidades Verdes, v.4, n.9, 2016, p. 102-113.

XAVIER, C. L.; NISHIJIMA, T. Percepção ambiental junto aos moradores do entorno do arroio Tabuão no bairro Esperança em Panambi/RS. Revista Eletrônica em Gestão, Educação e Tecnologia Ambiental. Santa Maria, v. 1, n. 1, p. 47-58, 2010. 